\title{
Glutamatergic Mechanisms Involved in Bladder Overactivity and Pudendal Neuromodulation in Cats
}

\author{
Jamie Uy, Michelle Yu, Xuewen Jiang, Cameron Jones, Bing Shen, Jicheng Wang, \\ James R. Roppolo, William C. de Groat, and Changfeng Tai
}

Department of Urology (J.U., M.Y., X.J., C.J., B.S., J.W., C.T.), Department of Pharmacology and Chemical Biology (J.R.R., W.C.D., C.T.), and Department of Bioengineering (C.T.),University of Pittsburgh, Pittsburgh, Pennsylvania; and Department of Urology, Qilu Hospital, Shandong University, Jinan, P.R. China (X.J.)

Received November 20, 2016; accepted April 19, 2017

\section{ABSTRACT}

The involvement of ionotropic glutamate receptors in bladder overactivity and pudendal neuromodulation was determined in $\alpha$-chloralose anesthetized cats by intravenously administering MK801 (a NMDA receptor antagonist) or CP465022 (an AMPA receptor antagonist). Infusion of $0.5 \%$ acetic acid (AA) into the bladder produced bladder overactivity. In the first group of 5 cats, bladder capacity was significantly $(P<0.05)$ reduced to $55.3 \pm 10.0 \%$ of saline control by AA irritation. Pudendal nerve stimulation (PNS) significantly $(P<0.05)$ increased bladder capacity to $106.8 \pm 15.0 \%$ and $106.7 \pm 13.3 \%$ of saline control at $2 \mathrm{~T}$ and $4 \mathrm{~T}$ intensity, respectively. $\mathrm{T}$ is threshold intensity for inducing anal twitching. MK801 at $0.3 \mathrm{mg} / \mathrm{kg}$ prevented the increase in capacity by $2 \mathrm{~T}$ or $4 \mathrm{~T}$ PNS. In the second group of 5 cats, bladder capacity was significantly $(P<0.05)$ reduced to
$49.0 \pm 7.5 \%$ of saline control by $\mathrm{AA}$ irritation. It was then significantly $(P<0.05)$ increased to $80.8 \pm 13.5 \%$ and $79.0 \pm$ $14.0 \%$ of saline control by $2 \mathrm{~T}$ and $4 \mathrm{~T}$ PNS, respectively. CP465022 at $0.03-1 \mathrm{mg} / \mathrm{kg}$ prevented the increase in capacity by $2 \mathrm{~T}$ PNS and at $0.3-1 \mathrm{mg} / \mathrm{kg}$ prevented the increase in capacity by 4 T PNS. In both groups, MK801 at $0.3 \mathrm{mg} / \mathrm{kg}$ and CP465022 at $1 \mathrm{mg} / \mathrm{kg}$ significantly $(P<0.05)$ increased the prestimulation bladder capacity (about $80 \%$ and $20 \%$, respectively) and reduced the amplitude of bladder contractions (about 30 and $20 \mathrm{cmH}_{2} \mathrm{O}$, respectively). These results indicate that NMDA and AMPA glutamate receptors are important for PNS to inhibit bladder overactivity and that tonic activation of these receptors also contributes to the bladder overactivity induced by AA irritation.

\section{Introduction}

The International Continence Society defines overactive bladder $(\mathrm{OAB})$ as a syndrome characterized by urgency with or without urge incontinence, usually with urinary frequency and nocturia (Abrams et al., 2002). The pathophysiology and etiology of OAB currently remain unknown (Miller and Hoffman, 2006; Wein and Rackley, 2006). About 33 million adults suffer from OAB in the United States (Coyne et al., 2011). In the general population $\mathrm{OAB}$ has an overall prevalence of $16-17 \%$ (Stewart et al., 2003). Current pharmacotherapies for OAB have either limited efficacy or significant side effects, causing many $\mathrm{OAB}$ patients to reject these drugs (Andersson and Wein, 2004; Chapple et al., 2008). When pharmacotherapy fails, the alternative treatments for $\mathrm{OAB}$ may include sacral, pudendal, or tibial neuromodulation therapies (van Kerrebroeck et al., 2007; Peters et al., 2009, 2010). However, the mechanisms of neuromodulation are currently not clear. Shedding new light on the mechanisms of bladder neuromodulation may lead to improved therapies for OAB.

This study is supported by the National Institutes of Health National Institutes of Diabetes and Digestive and Kidney Diseases [Grants DK-094905, DK-102427, and DK-111382].

https://doi.org/10.1124/jpet.117.240895.
Our previous studies in cats identified multiple inhibitory neurotransmitter mechanisms involved in sacral, pudendal, or tibial neuromodulation. Opioid and cannabinoid receptors are the major receptors involved in tibial neuromodulation (Zhang et al., 2015; Jiang et al., 2017), whereas GABA A $_{\text {, 5-HT, }}$ and $\beta$-adrenergic receptors are important in pudendal neuromodulation (Matsuta et al., 2013b; Schwen et al., 2013; Xiao et al., 2014; Kadow et al., 2016). The receptors involved in sacral neuromodulation include those involved in either tibial or pudendal neuromodulation such as opioid, $\mathrm{GABA}_{\mathrm{A}}$, and $\beta$-adrenergic receptors (Jiang et al., 2016; Bandari et al., 2017). In addition to these inhibitory neurotransmitters, the role of the excitatory glutamatergic neurotransmitter has also been identified in tibial or pudendal neuromodulation of bladder overactivity in cats. Metabotropic glutamate receptor 5 plays an important role in pudendal neuromodulation (Larson et al., 2011), whereas metabotropic glutamate receptor 2 and/or 3 plays a major role in tibial neuromodulation (Matsuta et al., 2013a). However, whether the ionotropic glutamate receptors (NMDA and AMPA) are also involved in neuromodulation of bladder overactivity in cats is still not determined.

This study examined the contribution of NMDA and AMPA receptors to pudendal neuromodulation of bladder overactivity in cats. The bladder was irritated by dilute acetic acid that 
activated the bladder nociceptive afferent $\mathrm{C}$-fibers to induce bladder overactivity. The pudendal nerve was electrically stimulated to inhibit the irritation-induced bladder overactivity. MK801 [(5S,10R)-(+)-5-Methyl-10,11-dihydro-5H-dibenzo [a,d]cyclohepten-5,10-imine hydrogen maleate] (an NMDA receptor antagonist) or CP465022, (3-(2-Chlorophenyl)-2-[2[6-[(diethylamino)methyl]-2-pyridinyl]ethenyl]-6-fluoro-4(3H)quinazolinone hydrochloride) (an AMPA receptor antagonist) were injected intravenously to suppress glutamatergic transmission and to determine the involvement of NMDA or AMPA receptors in pudendal inhibition. During the experiments it was also discovered that activation of these receptors is involved in the regulation of functional bladder capacity and the amplitude of reflex contractions of the overactive bladder.

\section{Method and Materials}

The Animal Care and Use Committee at the University of Pittsburgh approved the protocol and animal use in this study.

Surgical procedures. A total of 10 cats (8 female and 2 male, $2.5-4.5 \mathrm{~kg}$; Liberty Research, Waverly, NY) were used. During surgery the animals were anesthetized with isoflurane (2-5\% in oxygen) and then they were switched to $\alpha$-chloralose anesthesia (initial $65 \mathrm{mg} / \mathrm{kg}$ i.v. and supplemented as needed) during data collection. The left cephalic vein was catheterized for administration of fluid and drugs. The airway was kept patent by a tracheotomy. Systemic blood pressure was monitored by inserting a catheter into right carotid artery. A pulse oximeter (9847V; NONIN Medical, Plymouth, MN) was attached to the tongue to monitor the heart rate and blood oxygen. Through an abdominal incision, the ureters were exposed, tied, and transected for external drainage. A double lumen catheter was placed into the bladder via a small cut in the proximal urethra and fixed in place by a suture around the urethra. Saline or $0.5 \%$ acetic acid (AA) was slowly (1-4 ml/min) infused by a pump into the bladder via one lumen of the catheter. The other lumen was connected to a pressure transducer for bladder pressure measurement. A 3- to 4-cm incision was made in the sciatic notch lateral to the tail to expose the right pudendal nerve for implantation of a tripolar cuff electrode (NC223pt, MicroProbe, Gaithersburg, MD). The cuff electrode was connected to an electrical stimulator (S88; Grass Medical Instruments, Quincy, MA) via constant voltage stimulus isolators (SIU5; Grass Medical Instruments). All incisions were closed by sutures after the surgery.

Stimulation protocol and drug administration. Uniphasic rectangular pulses of $5-\mathrm{Hz}$ frequency and $0.2-\mathrm{m}$ pulse width were employed for pudendal nerve stimulation (PNS) using the cuff electrode. The intensity threshold (T) for evoking an observable anal sphincter twitch was determined at the beginning of the experiments. Based on our previous studies (Matsuta et al., 2013b; Zhang et al., 2015 ; Jiang et al., 2017), PNS of $2 \mathrm{~T}$ or $4 \mathrm{~T}$ intensity was used in this study to inhibit bladder overactivity.

Bladder capacity was defined as the bladder volume threshold to induce a bladder contraction of large amplitude $\left(>30 \mathrm{cmH}_{2} \mathrm{O}\right)$ and long duration ( $>20$ seconds). Initially, the bladder capacity was determined during multiple cystometrograms (CMGs) that were performed by slowly infusing the bladder with saline. Then, AA replaced the saline for bladder infusion, which produced bladder irritation, activated nociceptive C-fiber afferent nerves, and induced bladder overactivity.

For the first experimental group ( $n=5$ cats), once the control bladder capacity stabilized during repeated AA CMGs, the effect of PNS inhibition was determined by four AA CMGs in the following order: 1) control CMG without PNS, 2) CMG during 2T PNS, 3) CMG during $4 \mathrm{~T}$ PNS, 4) control CMG again to examine any poststimulation effect. Then the animals were given cumulative doses $(0.01,0.03,0.1$, and $0.3 \mathrm{mg} / \mathrm{kg}$ i.v.) of MK801 (an NMDA receptor antagonist; SigmaAldrich, St. Louis, MO). After each dose of MK801 was administered, the four CMGs (prestimulation control, 2T PNS, 4T PNS, poststimulation control) were repeated to determine the drug effects. A 10-minute waiting period after each dose of MK801 was used for the drug to take effect. A waiting period of 2-3 minutes was inserted between CMGs for the bladder to recover.

The same experimental protocol used in the first experimental group was also used in the second experimental group ( $n=5$ cats) to test the effects of cumulative doses $(0.001,0.003,0.01,0.03,0.1,0.3$ and $1.0 \mathrm{mg} / \mathrm{kg}$ i.v.) of CP465022 (an AMPA receptor antagonist; Tocris Bioscience, Bristol, UK).

Data analysis. Repeated measurements (2-3 CMGs) of saline control capacity in the same animal were averaged. Then, the bladder capacity was measured during each AA CMG and normalized to the averaged control capacity measured during saline infusion in each cat. The maximal amplitude of the bladder contraction at the end of each AA CMG was also measured. The data from different animals are presented as mean \pm standard error. Statistical significance $(P<0.05)$ was determined by repeated-measures analysis of variance followed by Dunnett's (one-way) or Bonferonni's (two-way) multiple comparison.

\section{Results}

Effect of MK801 on PNS inhibition of bladder overactivity. In this group of 5 cats, AA irritation-induced bladder overactivity significantly $(P<0.05)$ reduced bladder capacity to $55.3 \pm 10.0 \%$ of the control capacity $(11.8 \pm 2.6 \mathrm{ml})$ measured during saline CMGs. PNS inhibited the bladder overactivity and significantly $(P<0.05)$ increased bladder capacity to $106.8 \pm 15.0 \%$ (at $2 \mathrm{~T}$ ) and $106.7 \pm 13.3 \%$ (at $4 \mathrm{~T}$ ) of the saline control capacity (see first row of CMGs in Fig. 1 and the untreated condition in Fig. 2).

During the repeated AA CMG testing, MK801 dose dependently increased the prestimulation bladder capacity (Figs. 1 and 2 ) and reduced the amplitude of bladder contractions (Figs. 1 and Fig. 3). The prestimulation capacity was significantly $(P<0.05)$ increased to $134.5 \pm 30.3 \%$ of saline control at the $0.3 \mathrm{mg} / \mathrm{kg}$ dose of MK801 (Fig. 2). At the same dose, PNS at both $2 \mathrm{~T}$ and $4 \mathrm{~T}$ intensity failed to significantly increase the bladder capacity (Fig. 2) when it was applied during AA CMGs (Fig. 1).

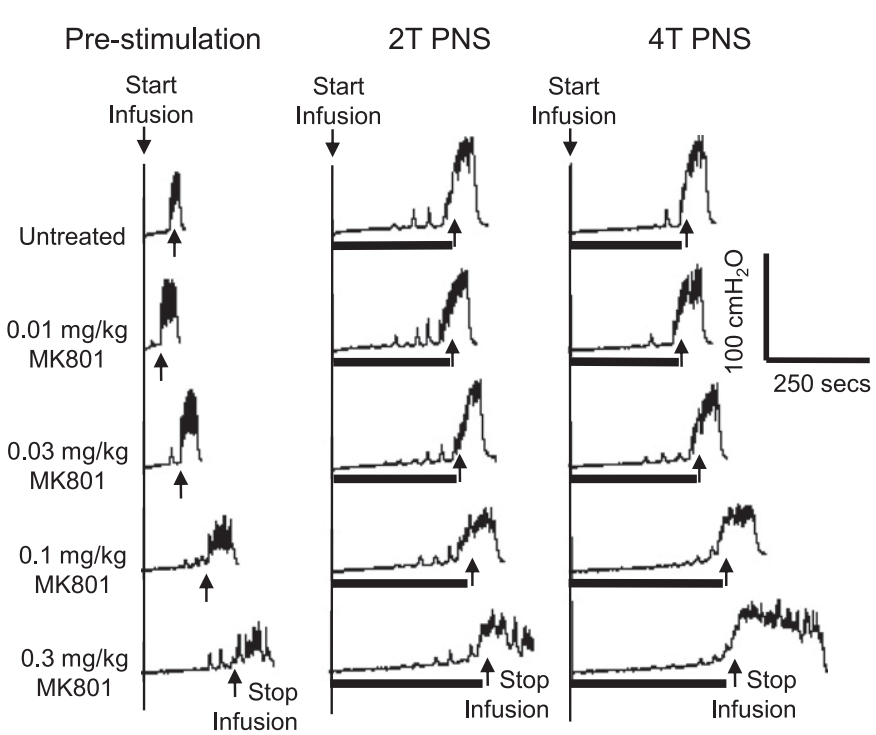

Fig. 1. Repeated CMG recordings at different cumulative doses of MK801 during acetic acid infusion with or without pudendal nerve stimulation (PNS). T, threshold PNS intensity to induce external anal sphincter twitch. Black bars under the bladder pressure traces indicate the durations of PNS ( $5 \mathrm{~Hz}, 0.2 \mathrm{~ms}, \mathrm{~T}=0.4 \mathrm{~V})$. Infusion rate $=4 \mathrm{ml} / \mathrm{min}$. 


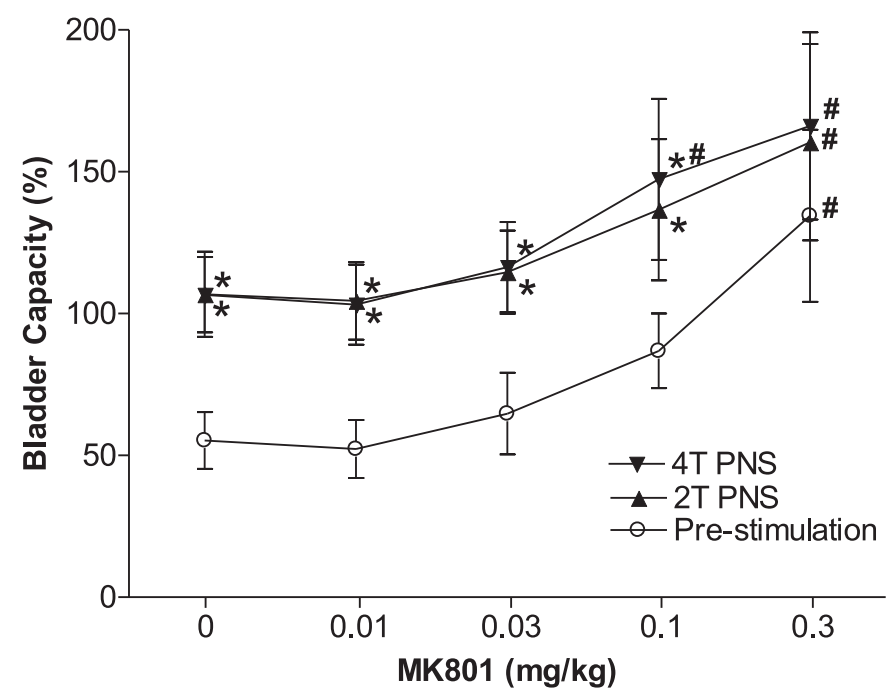

Fig. 2. Summarized results showing bladder capacity at different cumulative doses of MK801. Bladder capacity during acetic acid infusion was normalized to the capacity measured during saline infusion before any drug treatment or pudendal nerve stimulation (PNS). *Significantly $(P<0.05)$ different from prestimulation data at each drug dosage [2-way analysis of variance (ANOVA)]. \#Significantly $(P<0.05)$ different from the untreated condition in the same data group (1-way ANOVA). $n=$ 5 cats. PNS $(5 \mathrm{~Hz}, 0.2 \mathrm{~ms}, \mathrm{~T}=0.16-0.6 \mathrm{~V})$.

Effect of CP465022 on PNS inhibition of bladder overactivity. In this group of 5 cats, AA irritation-induced bladder overactivity significantly $(P<0.05)$ reduced bladder capacity to $49.0 \pm 7.5 \%$ of the control capacity $(12.0 \pm 2.0 \mathrm{ml})$ measured during saline CMGs. PNS inhibited the bladder overactivity and significantly $(P<0.05)$ increased bladder capacity to $80.8 \pm 13.5 \%$ (at $2 \mathrm{~T}$ ) and $79.0 \pm 14.0 \%$ (at $4 \mathrm{~T}$ ) of the saline control capacity (see the first row of CMGs in Fig. 4 and $0 \mathrm{mg} / \mathrm{kg}$ CP465022 condition in Fig. 5).

During the repeated AA CMG testing, CP465022 at a dose of $1.0 \mathrm{mg} / \mathrm{kg}$ significantly $(P<0.05)$ increased the prestimulation bladder capacity to $69.4 \pm 9.2 \%$ of saline control (Fig. 4 and Fig. 5). When PNS was applied during AA CMGs (Fig. 4), the bladder capacity could not be increased significantly by $2 \mathrm{~T}$

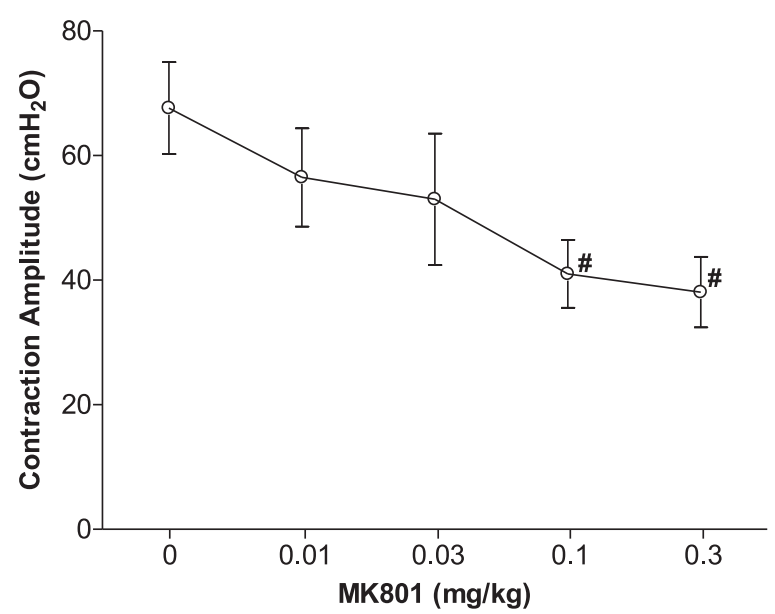

Fig. 3. Summarized results showing the amplitude of bladder contractions measured during prestimulation CMGs at different cumulative doses of MK801. \#Significantly $(P<0.05)$ different from untreated condition (1-way ANOVA). $n=5$ cats.
PNS at $0.03-1.0 \mathrm{mg} / \mathrm{kg}$ doses of CP465022 or by $4 \mathrm{~T}$ PNS at $0.3-1.0 \mathrm{mg} / \mathrm{kg}$ doses (Fig. 5). CP465022 also significantly $(P<$ 0.05 ) reduced the amplitude of bladder contractions at the $1.0 \mathrm{mg} / \mathrm{kg}$ dose (Fig. 6).

\section{Discussion}

Administration of either an NMDA (MK801) or an AMPA (CP465022) glutamatergic receptor antagonist suppresses PNS inhibition of bladder overactivity induced by AA irritation in chloralose anesthetized cats, indicating that both types of receptors play an important role in the inhibition. In addition, both antagonists increase bladder capacity and decrease the amplitude of the reflex bladder contractions, indicating that tonic activation of NMDA and AMPA receptors contributes to the AA-induced bladder overactivity. These results extend previous reports regarding the important role of glutamatergic excitatory transmission in the normal bladder function (Yoshiyama et al., 1993a; Matsumoto et al., 1995a, 1995b; Kakizaki et al., 1998) and demonstrate that glutamatergic excitatory mechanisms are also important in the reflex pathways mediating bladder overactivity.

Because glutamic acid is considered to be a major excitatory transmitter released by primary afferents in the spinal cord, it is likely that pudendal inhibition as well as bladder overactivity is modulated by actions of MK801 and CP465022 at primary afferent-interneuronal synapses in the spinal dorsal horn. Under basal conditions, AMPA are more important than NMDA receptors in generation of primary afferent evoked monosynaptic EPSPs in the dorsal horn (Larsson, 2009). However, NMDA activation contributes to more delayed excitatory synaptic responses under basal conditions and to the enhancement of excitatory transmission that occurs after nociceptive stimulation (Larsson, 2009). Although large doses of the AMPA and NMDA antagonists suppress both pudendal inhibition and bladder overactivity, a subtle difference was noted in the dose response studies of the two agents. CP465022 suppresses pudendal inhibition at doses that do not significantly alter bladder capacity or the amplitude of bladder contractions (Figs. 5 and 6), whereas MK-801 suppresses pudendal inhibition only in doses that also suppress bladder activity (Figs. 2 and 3). This suggests that transmission mediated by NMDA receptors is more important and/or more sensitive to block by MK801 in the bladder reflex pathway than in the pudendal inhibitory pathway. This difference may reflect an enhanced role of NMDA receptors in bladder reflexes after AA infusion into the bladder, which activates central nociceptive mechanisms and thereby may unmask an effect of MK801 on bladder reflex pathways. This possibility could be tested in future experiments by comparing the effects of the antagonists during saline CMGs in the absence of a nociceptive stimulus.

In addition to the contribution of ionotropic glutamate receptors to pudendal neuromodulation, previous studies in cats have shown that metabotropic glutamate receptor 5 (mGluR5) also plays an important role in pudendal neuromodulation of bladder overactivity induced by AA irritation (Larson et al., 2011). However, these receptors are not involved in the reflex mechanisms mediating bladder overactivity (Larson et al., 2011). Based on the known functions of mGluR5, it is likely that activation of these receptors during 


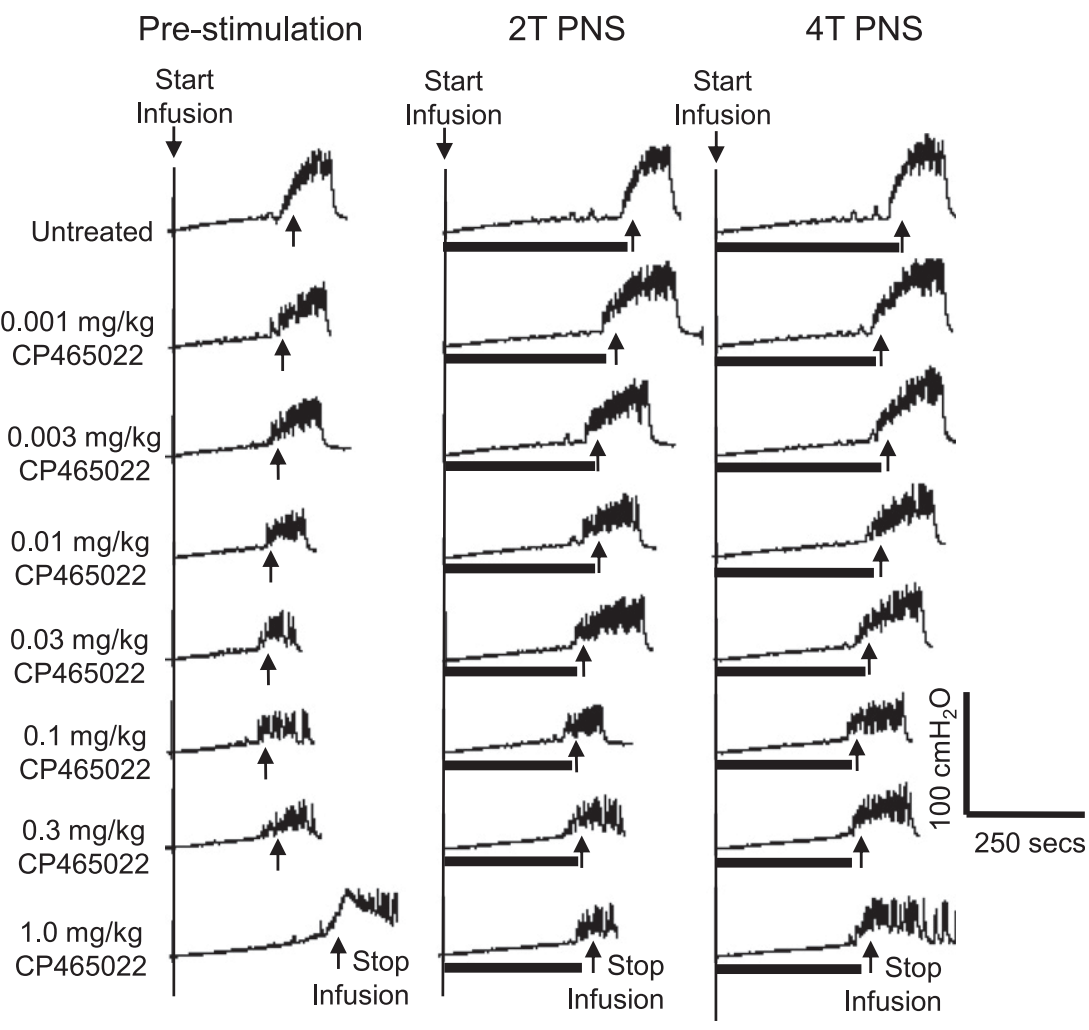

Fig. 4. Repeated CMG recordings at different cumulative doses of CP465022 during acetic acid infusion with or without pudendal nerve stimulation (PNS). T, threshold PNS intensity to induce external anal sphincter twitch. Black bars under the bladder pressure traces indicate the durations of PNS $(5 \mathrm{~Hz}, 0.2 \mathrm{~ms}, \mathrm{~T}=0.3 \mathrm{~V})$. Infusion rate $=1.5 \mathrm{ml} / \mathrm{min}$. pudendal neuromodulation facilitates synaptic transmission mediated by NMDA/AMPA receptors.

Pudendal neuromodulation of bladder overactivity also depends on multiple inhibitory transmitter mechanisms involving $\mathrm{GABA}_{\mathrm{A}}, \beta$-adrenergic, and 5 -HT receptors (Matsuta et al., 2013b; Schwen et al., 2013; Xiao et al., 2014; Kadow

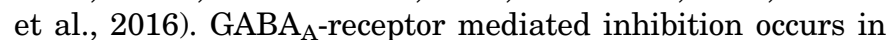
the spinal cord (Xiao et al., 2014), and therefore very likely involves glutamatergic activation of local GABAergic inhibitory interneurons. $\beta$-Adrenergic receptor-mediated inhibition occurs via reflex activation of sympathetic inhibitory pathways arising in the rostral lumbar spinal cord (Kadow et al., 2016), and therefore must involve a lumbosacral intersegmental excitatory pathway that also depends on glutamatergic excitatory synapses. The 5-HT receptor component of pudendal neuromodulation depends on serotonergic inputs to the sacral spinal cord from the raphe nuclei in the brain stem (Matsuta et al., 2013b; Schwen et al., 2013; Reese et al., 2014) and therefore must involve activation of raphe $5-\mathrm{HT}$ neurons by ascending glutamatergic projections from the sacral spinal cord to supraspinal sites. Thus it is likely that the glutamatergic antagonists administered intravenously in the present experiments suppress pudendal neuromodulation by acting at various sites within the central nervous system.

Our study showing that AMPA and NMDA receptors are involved in pudendal neuromodulation differs from a previous study of sacral neuromodulation of bladder overactivity in rats, which showed that spinal NMDA receptors but not spinal non-NMDA receptors play a key role in sacral neuromodulation (Riazimand and Mense, 2005). This may indicate a species difference or a difference in the mechanisms involved in the two types of neuromodulation. In cats, sacral neuromodulation of bladder overactivity depends in part on activation of opioid receptors and supraspinal $\mathrm{GABA}_{\mathrm{A}}$ receptors (Jiang et al., 2016; Bandari et al., 2017), whereas pudendal neuromodulation does not involve opioid receptors but depends in part, as mentioned above, on activation of spinal $\mathrm{GABA}_{\mathrm{A}}$ receptors (Mally et al., 2013; Xiao et al., 2014).

It is likely that MK801 and CP465022 also act at multiple sites in the central nervous system to increase bladder capacity and reduce the amplitude of bladder contractions. The micturition reflex is mediated by a spinobulbospinal

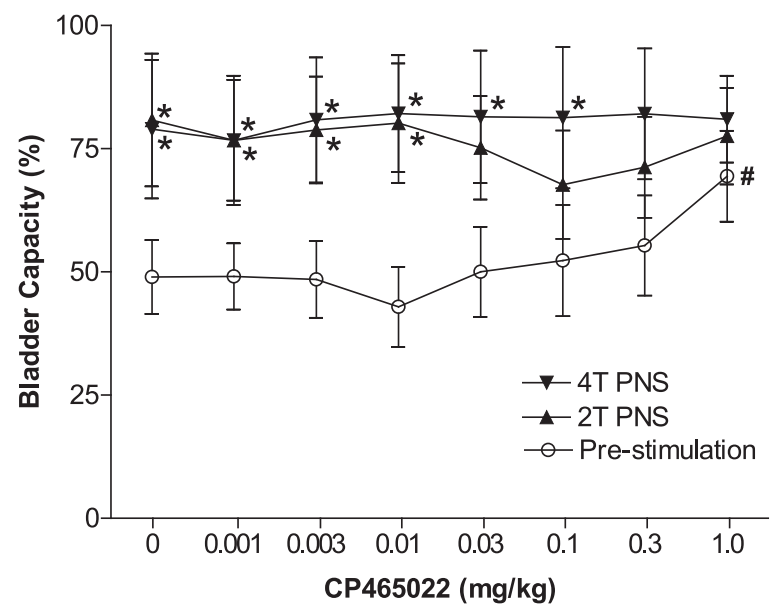

Fig. 5. Summarized results showing bladder capacity at different cumulative doses of CP465022. Bladder capacity was normalized to the capacity measured during saline infusion before any drug treatment or pudendal nerve stimulation (PNS). *Significantly $(P<0.05)$ different from prestimulation data at each drug dosage (2-way ANOVA). \#Significantly $(P<0.05)$ different from the untreated condition in the same data group (1-way ANOVA). $n=5$ cats. PNS ( $5 \mathrm{~Hz}, 0.2 \mathrm{~ms}, \mathrm{~T}=0.15-1.6 \mathrm{~V})$. 


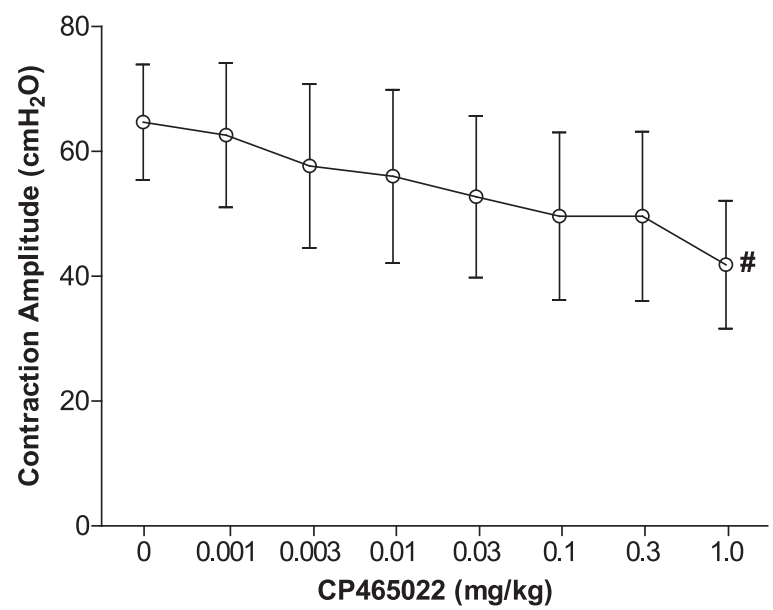

Fig. 6. Summarized results showing the amplitude of bladder contractions measured during prestimulation CMGs at different cumulative doses of CP465022. \#Significantly $(P<0.05)$ different from untreated condition (1-way ANOVA). $n=5$ cats.

pathway consisting of 1 ) an ascending limb projecting from the sacral spinal cord to the brain stem, 2) supraspinal circuitry in the periaqueductal gray and the pontine micturition center, and 3) a descending limb from the pontine micturition center back to the sacral spinal cord (Fowler et al., 2008). In rats, glutamate has been identified as an excitatory transmitter in each segment of this pathway (Yoshiyama et al., 1993a; Matsumoto et al., 1995a,b; Kakizaki et al., 1998). AMPA and NMDA glutamatergic antagonists administered systemically, intrathecally, or intracerebroventricularly suppress bladder reflexes during saline or AA CMGs in urethane anesthetized rats (Yoshiyama et al., 1993b, 1997). The antagonists also suppress c-fos expression induced in spinal dorsal horn neurons by AA irritation of the bladder (Kakizaki et al., 1996), indicating AMPA and NMDA receptors have an important role in the afferent limb of the overactive bladder reflex triggered by a nociceptive stimulus. During saline CMGs in unanesthetized decerebrate rats (Yoshiyama et al., 1994, 1997), AMPA antagonists are also effective in suppressing reflex bladder activity, whereas NMDA antagonists are ineffective or facilitate bladder activity. On the basis of these experiments it was proposed that excitatory glutamatergic transmission in the normal micturition reflex pathway in rats is mediated primarily by AMPA receptors and that the contribution of NMDA receptors is only unmasked when transmission mediated by AMPA receptors is depressed by an anesthetic. On the other hand, patch clamp recording in spinal cord slices of neonatal rats revealed that both AMPA and NMDA receptors are involved in excitatory transmission in spinal reflex pathways to the parasympathetic preganglionic neurons (Araki and de Groat, 1996, 1997; Miura et al., 2003) as well as in axonal projections from the lateral funiculus to these neurons (Miura et al., 2001). These axonal projections could be part of propriospinal or supraspinal pathways.

Relatively little information is available about the role of glutamatergic transmission in bladder reflexes in cats. It has been reported that glutamatergic receptor agonists injected into the pontine micturition center in decerebrate cats induce voiding or facilitate reflex bladder contractions (Mallory et al., 1991), whereas intrathecal injections of MK-801 or kynurenic acid, a broad spectrum glutamatergic receptor antagonist, blocks bladder contractions elicited by electrical stimulation of the pontine micturition center (Iwabuchi, 1997). However the latter contractions are not blocked by CNQX, a non-NMDA receptor antagonist. Iontophoretic application of glutamatergic receptor agonists have an excitatory effect on bladder parasympathetic preganglionic neurons in the cat spinal cord (de Groat and Ryall, 1968; De Groat, 1971) and iontophoretic application of kynurenic acid blocks the firing of these neurons elicited by electrical stimulation of the pontine micturition center (Iwabuchi, 1997). These studies indicate that in cats NMDA receptors in the spinal cord are involved in the descending limb of the micturition reflex pathway, whereas spinal AMPA receptors are not involved in this pathway. Therefore, in the present study the reduction in contraction amplitude by MK801 (Fig. 3), which occurs by the same dose (0.1-0.3 mg/kg i.v.) in cats (Fig. 3) and rats (Yoshiyama et al., 1993a), can be explained very well by the important role of spinal NMDA receptors in the descending limb of the micturition reflex pathway. On the other hand, the reduction in contraction amplitude as well as the increase in bladder capacity by CP465022 (Fig. 6) is probably caused by targeting AMPA receptors in the ascending limb of the micturition reflex or in the periaqueductal gray-pontine circuitry, thereby reducing the input from the pontine micturition center to the sacral spinal cord.

In MK801-treated cats, pudendal inhibition was eliminated only when the prestimulation bladder capacity was more than double the capacity measured in the untreated condition (see Fig. 2). This raises a concern that the loss of pudendal inhibition might not be due to the blockade of NMDA receptors in the pudendal-to-bladder inhibitory pathway, but instead could be due to the large bladder volume that produces a strong micturition reflex that overcomes the pudendal inhibition or due to the bladder reaching a maximal volume that cannot be further increased by PNS. However, the data in this study support the opposite conclusion. At the $3 \mathrm{mg} / \mathrm{kg}$ dose of MK801, the prestimulation capacity is only $134.5 \pm 30.3 \%$ of saline control capacity (Fig. 3), which is not likely to be the maximal bladder volume during an inhibition. Our previous studies in cats (Matsuta et al., 2013b; Schwen et al., 2013) showed that during the inhibition produced by PNS and/or drugs, the micturition reflex can occur at a bladder volume about $300-400 \%$ of saline control capacity, indicating that the maximal bladder volume is much larger. In addition, the micturition reflex after $0.3 \mathrm{mg} / \mathrm{kg}$ of MK801 seems to be weaker because the amplitude of micturition contraction is only $50 \%$ of the control (see the prestimulation CMG in Figs. 1 and 3). This may be due to MK801 suppressing glutamatergic transmission in the central descending limb of the spinobulbospinal micturition reflex pathway, thereby producing a weaker micturition reflex rather than a stronger one. Because the micturition reflex is weak and the maximal bladder volume for inducing a reflex is not reached, the $3 \mathrm{mg} / \mathrm{kg}$ dose of MK801 must have suppressed the micturition reflex and blocked pudendal inhibition at the same time. Otherwise, a significant increase in bladder capacity should have occurred during PNS.

In summary, this study in cats revealed that both NMDA and AMPA glutamatergic mechanisms are involved in the generation of reflex bladder overactivity as well as in pudendal neuromodulation of this activity. These results together 
with previous reports showing the involvement of inhibitory neurotransmitters (Kadow et al., 2016; Matsuta et al., 2013b; Schwen et al., 2013; Xiao et al., 2014) suggest that the pudendal neuromodulation depends on the activation of NMDA and AMPA glutamatergic excitatory transmission, which in turn stimulates the inhibitory pathways that suppress reflex bladder activity.

\section{Authorship Contributions}

Participated in research design: Uy, Yu, Jiang, Jones, Shen, Wang, Roppolo, de Groat, and Tai.

Conducted experiments: Uy, Yu, Jiang, Jones, Shen, Wang, Roppolo, de Groat, and Tai.

Contributed new reagents or analytic tools: Uy, Yu, Jiang, Jones, Shen, Wang, Roppolo, de Groat, and Tai.

Performed data analysis: Uy, Yu, Jiang, Jones, Shen, Wang, Roppolo, de Groat, and Tai.

Wrote or contributed to the writing of the manuscript: $\mathrm{Uy}, \mathrm{Yu}$, Jiang, Jones, Shen, Wang, Roppolo, de Groat, and Tai.

\section{References}

Abrams P, Cardozo L, Fall M, Griffiths D, Rosier P, Ulmsten U, van Kerrebroeck P, Victor A, and Wein A (2002) The standardisation of terminology of lower urinary tract function: report from the Standardisation Sub-committee of the International Continence Society. Am J Obstet Gynecol 187:116-126.

Andersson KE and Wein AJ (2004) Pharmacology of the lower urinary tract: basis for current and future treatments of urinary incontinence. Pharmacol Rev 56:581-631.

Araki I and De Groat WC (1996) Unitary excitatory synaptic currents in preganglionic neurons mediated by two distinct groups of interneurons in neonatal rat sacral parasympathetic nucleus. J Neurophysiol 76:215-226.

Araki I and de Groat WC (1997) Developmental synaptic depression underlying reorganization of visceral reflex pathways in the spinal cord. $J$ Neurosci 17: 8402-8407.

Bandari J, Bansal U, Zhang Z, Shen B, Wang J, Lamm V, Chang V, Roppolo JR, de Groat WC, and Tai C (2017) Neurotransmitter mechanisms underlying sacral neuromodulation of bladder overactivity in cats. Neuromodulation 20:81-87.

Chapple CR, Khullar V, Gabriel Z, Muston D, Bitoun CE, and Weinstein D (2008) The effects of antimuscarinic treatments in overactive bladder: an update of a systematic review and meta-analysis. Eur Urol 54:543-562.

Coyne KS, Sexton CC, Vats V, Thompson C, Kopp ZS, and Milsom I (2011) National community prevalence of overactive bladder in the United States stratified by sex and age. Urology 77:1081-1087.

DeGroat WC (1971) Inhibition and excitation of sacral parasympathetic neurons by visceral and cutaneous stimuli in the cat. Brain Res 33:499-503.

de Groat WC and Ryall RW (1968) The identification and characteristics of sacral preganglionic parasympathetic neurons. J Physiol 196:533-577.

Fowler CJ, Griffiths D, and de Groat WC (2008) The neural control of micturition. Nat Rev Neurosci 9:453-466.

Iwabuchi N (1997) Sacral glutamatergic transmission in the descending limb of the micturition reflex in the cat. Fukuoka Igaku Zasshi 88:30-38.

Jiang X, Fuller TW, Bandari J, Bansal U, Zhang Z, Shen B, Wang J, Roppolo JR, de Groat WC, and Tai C (2016) Contribution of $\mathrm{GABA}_{\mathrm{A}}$, glycine, and opioid receptors to sacral neuromodulation of bladder overactivity in cats. J Pharmacol Exp Ther 359:436-441.

Jiang X, Yu M, Uy J, Fuller TW, Jones C, Shen B, Wang J, Roppolo JR, de Groat WC, and Tai C (2017) Role of cannabinoid receptor type 1 in tibial and pudendal neuromodulation of bladder overactivity in cats. Am J Physiol Renal Physiol 312:F482-F488.

Kadow BT, Lyon TD, Zhang Z, Lamm V, Shen B, Wang J, Roppolo JR, de Groat WC, and Tai C (2016) Sympathetic $\beta$-adrenergic mechanism in pudendal inhibition of nociceptive and non-nociceptive reflex bladder activity. Am J Physiol Renal Physiol 311:F78-F84.

Kakizaki H, Yoshiyama M, and de Groat WC (1996) Role of NMDA and AMPA glutamatergic transmission in spinal c-fos expression after urinary tract irritation. Am J Physiol 270:R990-R996.

Kakizaki H, Yoshiyama M, Roppolo JR, Booth AM, and De Groat WC (1998) Role of spinal glutamatergic transmission in the ascending limb of the micturition reflex pathway in the rat. $J$ Pharmacol Exp Ther 285:22-27.

Larson JA, Ogagan PD, Chen G, Shen B, Wang J, Roppolo JR, de Groat WC, and Tai $\mathrm{C}$ (2011) Involvement of metabotropic glutamate receptor 5 in pudendal inhibition of nociceptive bladder activity in cats. J Physiol 589:5833-5843.
Larsson M (2009) Ionotropic glutamate receptors in spinal nociceptive processing. Mol Neurobiol 40:260-288.

Mallory BS, Roppolo JR, and de Groat WC (1991) Pharmacological modulation of the pontine micturition center. Brain Res 546:310-320.

Mally AD, Matsuta Y, Zhang F, Shen B, Wang J, Roppolo JR, de Groat WC, and Tai C (2013) Role of opioid and metabotropic glutamate 5 receptors in pudendal inhibition of bladder overactivity in cats. $J$ Urol 189:1574-1579.

Matsumoto G, Hisamitsu T, and de Groat WC (1995a) Non-NMDA glutamatergic excitatory transmission in the descending limb of the spinobulbospinal micturition reflex pathway of the rat. Brain Res 693:246-250.

Matsumoto G, Hisamitsu T, and de Groat WC (1995b) Role of glutamate and NMDA receptors in the descending limb of the spinobulbospinal micturition reflex pathway of the rat. Neurosci Lett 183:58-61.

Matsuta Y, Mally AD, Zhang F, Shen B, Wang J, Roppolo JR, de Groat WC, and Tai C (2013a) Contribution of opioid and metabotropic glutamate receptor mechanisms to inhibition of bladder overactivity by tibial nerve stimulation. Am J Physiol Regul Integr Comp Physiol 305:R126-R133.

Matsuta Y, Schwen Z, Mally AD, Shen B, Wang J, Roppolo JR, de Groat WC, and Tai $\mathrm{C}(2013 \mathrm{~b})$ Effect of methysergide on pudendal inhibition of micturition reflex in cats. Exp Neurol 247:250-258.

Miller J and Hoffman E (2006) The causes and consequences of overactive bladder. $J$ Womens Health (Larchmt) 15:251-260.

Miura A, Kawatani M, and de Groat WC (2001) Excitatory synaptic currents in lumbosacral parasympathetic preganglionic neurons elicited from the lateral funiculus. J Neurophysiol 86:1587-1593.

Miura A, Kawatani M, and De Groat WC (2003) Excitatory synaptic currents in lumbosacral parasympathetic preganglionic neurons evoked by stimulation of the dorsal commissure. J Neurophysiol 89:382-389.

Peters KM, Macdiarmid SA, Wooldridge LS, Leong FC, Shobeiri SA, Rovner ES, Siegel SW, Tate SB, Jarnagin BK, Rosenblatt PL, et al. (2009) Randomized trial of percutaneous tibial nerve stimulation versus extended-release tolterodine: results from the overactive bladder innovative therapy trial. J Urol 182:1055-1061.

Peters KM, Killinger KA, Boguslawski BM, and Boura JA (2010) Chronic pudendal neuromodulation: expanding available treatment options for refractory urologic symptoms. Neurourol Urodyn 29:1267-1271.

Reese J, Xiao Z, Schwen Z, Matsuta Y, Shen B, Wang J, Roppolo JR, de Groat WC, and Tai C (2014) Effects of duloxetine and WAY100635 on pudendal inhibition of bladder overactivity in cats. J Pharmacol Exp Ther 349:402-407.

Riazimand SH and Mense S (2005) Interaction between neurotransmitter antagonists and effects of sacral neuromodulation in rats with chronically hyperactive bladder. BJU Int 96:900-908.

Schwen Z, Matsuta Y, Shen B, Wang J, Roppolo JR, de Groat WC, and Tai C (2013) Involvement of 5-HT3 receptors in pudendal inhibition of bladder overactivity in cats. Am J Physiol Renal Physiol 305:F663-F671.

Stewart WF, Van Rooyen JB, Cundiff GW, Abrams P, Herzog AR, Corey R, Hunt TL and Wein AJ (2003) Prevalence and burden of overactive bladder in the United States. World J Urol 20:327-336.

van Kerrebroeck PE, van Voskuilen AC, Heesakkers JP, Lycklama á Nijholt AA Siegel S, Jonas U, Fowler CJ, Fall M, Gajewski JB, Hassouna MM, et al. (2007) Results of sacral neuromodulation therapy for urinary voiding dysfunction: outcomes of a prospective, worldwide clinical study. J Urol 178:2029-2034.

Wein AJ and Rackley RR (2006) Overactive bladder: a better understanding of pathophysiology, diagnosis and management. J Urol 175:S5-S10.

Xiao Z, Reese J, Schwen Z, Shen B, Wang J, Roppolo JR, de Groat WC, and Tai C (2014) Role of spinal GABA $\mathrm{A}_{\mathrm{A}}$ receptors in pudendal inhibition of nociceptive and nonnociceptive bladder reflexes in cats. Am $J$ Physiol Renal Physiol 306: F781-F789.

Yoshiyama M, Roppolo JR, and de Groat WC (1993a) Effects of MK-801 on the micturition reflex in the rat-possible sites of action. J Pharmacol Exp Ther $\mathbf{2 6 5}$ 844-850.

Yoshiyama M, Roppolo JR, and de Groat WC (1997) Effects of LY215490, a competitive alpha-amino-3-hydroxy-5-methylisoxazole-4-propionic acid (AMPA) receptor antagonist, on the micturition reflex in the rat. $J$ Pharmacol Exp Ther $\mathbf{2 8 0}$ : 894-904.

Yoshiyama M, Roppolo JR, and De Groat WC (1994) Alteration by urethane of glutamatergic control of micturition. Eur J Pharmacol 264:417-425.

Yoshiyama M, Roppolo JR, Thor KB, and de Groat WC (1993b) Effects of LY274614, a competitive NMDA receptor antagonist, on the micturition reflex in the urethaneanaesthetized rat. $\mathrm{Br} J$ Pharmacol 110:77-86.

Zhang Z, Slater RC, Ferroni MC, Kadow BT, Lyon TD, Shen B, Xiao Z, Wang J, Kang A, Roppolo JR, et al. (2015) Role of $\mu, \kappa$, and $\delta$ opioid receptors in tibial inhibition of bladder overactivity in cats. J Pharmacol Exp Ther 355:228-234.

Address correspondence to: Dr. Changfeng Tai, Department of Urology, University of Pittsburgh, 700 Kaufmann Building, Pittsburgh, PA 15213. E-mail: cftai@pitt.edu 